\title{
The Fellowship of Postgraduate Medicine and the National Association of Clinical Tutors - a confluence of opportunity
}

\author{
P. Turner ${ }^{1}$, M.W.N. Nicholls ${ }^{2}$ and B.I. Hoffbrand ${ }^{3}$ \\ ${ }^{1}$ President, Fellowship of Postgraduate Medicine, ${ }^{2}$ Hon Secretary, Fellowship of Postgraduate Medicine and \\ ex-Chairman, National Association of Clinical Tutors and ${ }^{3}$ Editor, Postgraduate Medical Journal.
}

We have previously given an account of the pioneering role of the Fellowship of Postgraduate Medicine in co-ordinating and providing an impetus for the development of postgraduate medical education in London and throughout the United Kingdom. ${ }^{1}$ Sir David Innes Williams in the same diamond jubilee issue of the Journal ${ }^{2}$ provided an account of the subsequent evolution of postgraduate medical education in the UK which is almost entirely based on the three great estates of the Royal Colleges (and Faculties), the Universities and the National Health Service. $\mathrm{He}$ discussed the problems there have been in coordinating these separate interests. The General Medical Council given a responsibility for coordinating all stages of medical education by the Medical Act of 1978 has had problems in securing acceptance of its policies. ${ }^{2}$ The Council for Postgraduate Medical Education (CPME) for England and Wales which was set up in 1971 as a forum for the various interested parties has not made a great impact and has recently been replaced by a new body, the Standing Committee on Postgraduate Medical Education (SCOPME) under the Chairmanship of Professor Dame Barbara Clayton. There is now a separate CPME for Wales as well as the Scottish Council for Postgraduate Medical Education.

The role in postgraduate education of the Fellowship of Postgraduate Medicine which stands outside and is independent of the major professional, university and government bodies has for a number of years been confined to publication of the Postgraduate Medical Journal; the last postgraduate course, organized by the Fellowship, was in 1974. Recently, however, the Fellowship has expanded its activities into other areas. It has always been eager to promote clinical research, particularly for young investigators in training. It now provides the secretarial and organizational basis for the European Medical Research Group (EMRG) in this country. The Fel-

Correspondence: B.I. Hoffbrand, D.M., F.R.C.P., Fellowship of Postgraduate Medicine, 6 St Andrew's Place, London NW1 4LB. lowship assists in the organization and promotion of regular meetings of EMRG in London and it is hoped that meetings may also be arranged in other parts of the country. The proceedings of these meetings are published in the Postgraduate Medical Journal. The Fellowship also offers research and travelling fellowships to young clinical research workers to assist them in their work.

The Fellowship has, since July 1988, also provided facilities for the secretarial and organizational requirements of the National Association of Clinical Tutors (NACT), the co-ordinating body of tutors in postgraduate centres throughout the United Kingdom. The NACT is also expanding the range of its activities to meet the changing needs of clinical tutors. It is involved, among many other activities, in career guidance and counselling ${ }^{3}$ and runs courses on educational techniques. It awards Travelling Fellowships to the USA and to Europe, and publishes $A$ Handbook for Clinical Tutors and Directory of Postgraduate Medical Centres. The major coming together of the clinical tutors takes place at the annual winter meeting. This issue of the Journal (page 262) carries an account by Dr Ieuan Davies, Regional Director of Postgraduate Medical Education for Northern Scotland, of the most recent meeting, when the new association of NACT with the Fellowship of Postgraduate Medicine was welcomed.

Now cohabiting at $6 \mathrm{St}$ Andrew's Place, the two organizations, though not married, will, we hope, develop a close and fruitful relationship. The Fellowship will now have a direct, albeit modest, involvement in the mainstream of the several stages of postgraduate medical education, the purpose of which is to provide all graduates with training through approved posts giving appropriate experience with additional course study, diplomas and accreditation where indicated, to provide ultimately satisfactory and rewarding career posts in general practice, the hospital service or other fields.

The NACT is, like the Fellowship, independent of the health service and indeed of the universities which its members represent. However it works closely with 
Postgraduate Deans and the Colleges and Faculties to ensure adequate provision for all doctors in training at District level as well as the continuing medical education of those in senior posts. NACT represents the grass roots of hospital based postgraduate medical education where so much of the action is. It is hoped that the stable organizational base NACT now has will make it easier for it to be able to meet the challenges of the changes that are occurring so rapidly in the postgraduate field. 'Achieving a Balance', duty rotas for junior doctors, and an increasing mobility of doctors within Europe are just three such areas. It will also need to come to terms with the eventual consequences for medical audit, training and research of the

\section{References}

1. Hoffbrand, B.I. The Fellowship of Postgraduate Medicine and the Postgraduate Medical Journal. Postgrad Med J 1985, 61: 1-2.

2. Innes Williams, D. The evolution of postgraduate medical education. Postgrad Med J 1985, 61: 875-886. government's white paper on the review of the National Health Service 'Working for Patients'. The Postgraduate Medical Journal which is being sent to all NACT members should provide a vehicle for improved communication between tutors and a forum for constructive debate about ends and the means to them. The tutors are certainly warmly invited to send in contributions to an expanded 'Scenes from Postgraduate Life' column and other suggestions. They are the individuals, more than most, who know at close quarters the problems within postgraduate medical education. With the Fellowship of Postgraduate Medicine and NACT now working together, we can hope to help with solutions.

3. Hoffbrand, B.I. Counselling for counsellors. Postgrad Med J 1988, 64: 720-722. 